\title{
Between the Reasonable and the Particular: Deflating Autonomy in the Legal Regulation of Informed Consent to Medical Treatment
}

\author{
Michael Dunn ${ }^{1}$ D $\cdot$ K. W. M. Fulford ${ }^{2} \cdot$ Jonathan Herring ${ }^{3} \cdot$ Ashok Handa $^{4}$
}

Published online: 30 June 2018

(c) The Author(s) 2018

\begin{abstract}
The law of informed consent to medical treatment has recently been extensively overhauled in England. The 2015 Montgomery judgment has done away with the long-held position that the information to be disclosed by doctors when obtaining valid consent from patients should be determined on the basis of what a reasonable body of medical opinion agree ought to be disclosed in the circumstances. The UK Supreme Court concluded that the information that is material to a patient's decision should instead be judged by reference to a new two-limbed test founded on the notions of the 'reasonable person' and the 'particular patient'. The rationale outlined in Montgomery for this new test of materiality, and academic comment on the ruling's significance, has focused on the central ethical importance that the law now (rightfully) accords to respect for patient autonomy in the process of obtaining consent from patients. In this paper, we dispute the claim that the new test of materiality articulated in Montgomery equates with respect for autonomy being given primacy in re-shaping the development of the law in this area. We also defend this position, arguing that our revised interpretation of Montgomery's significance does not equate with a failure by the courts to give due legal consideration to what is owed to patients as autonomous decision-makers in the consent process. Instead, Montgomery correctly implies that doctors are ethically (and legally) obliged to attend to a number of relevant ethical considerations in framing decisions about consent to treatment, which include subtle interpretations of the values of autonomy and wellbeing. Doctors should give appropriate consideration to how these values are fleshed out and balanced in context in order to specify precisely what information ought to be disclosed to a patient as a requirement of obtaining consent, and as a core component of shared decision-making within medical encounters more generally.
\end{abstract}

Keywords Informed consent · Shared decision making · Patient autonomy · Reasonable person $\cdot$ Medical law

Michael Dunn

michael.dunn@ethox.ox.ac.uk

Extended author information available on the last page of the article 


\section{Introduction: Montgomery and the New Test of Materiality for Risk Disclosure}

Montgomery $v$ Lanarkshire Health Board [26] (from this point on: Montgomery) is a recent UK Supreme Court judgment that overturned the 1985 House of Lords decision in Sidaway [42] to govern the practice of informed consent by applying the well-established Bolam [2] professional standard of non-negligent care. Briefly, the facts of the Montgomery case were as follows: Mrs. Montgomery suffers from diabetes and is of short stature. Shoulder dystocia arose as a complication during the vaginal delivery of her baby, leading to the occlusion of the umbilical cord and causing the baby to suffer from a brachial plexus injury that required life-long, intensive medical care and treatment. Mrs. Montgomery sought damages in negligence on the grounds that she ought to have been provided with information about the risk of shoulder dystocia (a risk estimated at 9-10\%, given Mrs. Montgomery's presenting condition), and of the alternative option of an elective Caesarean Section. Her obstetrician, Dr. McLellan, argued that this information did not meet the requirements of the Bolam standard because the consequent risk that the baby would suffer a grave permanent injury was very small indeed-less than $0.1 \%$ of cases give rise to prolonged hypoxia, and less than $0.2 \%$ of cases result in brachial plexus injury from the McRoberts manoeuvre that is clinically indicated to resolve shoulder dystocia.

The lower courts accepted Dr. McLellan's defence in general terms, but, in the Supreme Court, the justices' reasoning hinged predominantly on precisely what standard ought to be endorsed by the court in order to determine whether Dr. McLellan had disclosed information about the risks facing Mrs. Montgomery correctly. Incorporating an approach borrowed in its entirety from Rogers $v$ Whitaker [36], a 25-year-old Australian High Court judgment, the seven justices of the UK Supreme Court concluded unanimously that information about risk that was material to a patient's decision to give or withhold consent should be judged by reference to a new two-limbed test. This new test of materiality requires risk to be disclosed when, in the circumstances of the particular case:

1. A reasonable person in the patient's position would attach significance to the risk, or

2. The doctor is or should reasonably aware that the particular patient would be likely to attach significance to it [27].

On the basis of this test, the justices concluded that the risk of shoulder dystocia ought to have been disclosed to Mrs. Montgomery, irrespective of the low consequent risk that this complication would lead to a severe negative outcome for the baby. It was also accepted that, had this risk been disclosed and Mrs. Montgomery had been offered a caesarean section, she would not have opted for a vaginal delivery and the disability to the child would not have occurred. The negligence had, therefore, been shown to have caused a harm.

The role and scope of the application of this new test of materiality in the treatment decision-making context is also worthy of brief discussion. Montgomery 
focused largely on the question of risk disclosure: essentially what risks ought to be disclosed in order for valid informed consent to have been obtained. However, judgements made about information about risk that should be disclosed to a patient will often have a direct impact on the range of alternative or variant treatments that a patient should be offered accordingly. This was indeed the case in Montgomery, where the requirement to disclose information about the risk of shoulder dystocia led to a subsequent and direct requirement for Mrs. Montgomery to have been advised about the alternative of an elective Caesarean Section [28].

Recent commentary on Montgomery has drawn attention to a core tension that now exists between the new standard by which risk disclosure is to be judged, and, as part of the same doctor-patient interaction, the requirement to offer alternative treatments to patients that are judged as reasonable to offer on the basis of the Bolam standard [24]. In cases such as Birch [1] the Bolam-mandated alternative treatment options that ought to have been offered to a patient was a decision to be taken prior to the requirement to tailor risk disclosure requirements around the reasonable patient's concerns, on the basis of the reasonable alternative options identified by the doctors concerned. However, in Montgomery, the question about which risks associated with a vaginal delivery should be disclosed was settled in a way that had the direct effect of determining that an alternative delivery option, a Caesarean Section, was now reasonable to be offered to Mrs. Montgomery. One interpretation of the connection made between risk disclosure and the requirement to offer the Caesarean Section to Mrs. Montgomery is that the new test of materiality bleeds into the question of which specific alternative or variant treatments ought to be made available to the patient. This might mean that the question about which alternative treatments should be offered to patients would be partly determined by a test identical to, or at least derived from, the new test of materiality for risk disclosure in Montgomery. Alternatively, the two standards might continue to co-exist in subsequent judgments; there will separate questions, judged by different legal standards, about what risks should be disclosed to patients and what range of alternative or variant treatments should be offered to patients. The residual legal uncertainty post-Montgomery about the extension of the new test of materiality to other aspects of the treatment decision-making process leads us to focus our attention in our subsequent analysis on the issue of risk disclosure alone.

\section{Montgomery's Moral Narrative}

The rationale presented for the new test of materiality for risk disclosure, and academic comment on the ruling's significance, has focused on the central ethical importance that the law now rightfully accords to respect for patient autonomy in determining how consent ought to be obtained lawfully by medical practitioners [7]. This 'moral narrative' is articulated in a number of related ways. For the justices themselves, the ethical and professional requirement of respect for patient autonomy lies explicitly in the background of their reasoning, [29] or implicitly in their presentation of a rights-based account to determine what is owed to patients with regards to the information they need to give meaningful permission to treatment [30]. 
Academic commentary has been even more explicit in connecting the new materiality test with the ethical principle of respect for autonomy. Poole [35] interprets the significance of the Montgomery judgement in terms of patient autonomy triumphing over medical paternalism, whilst, for Farrell and Brazier [11], the Supreme Court's explicit recognition of the importance of recognising patient autonomy in clinical judgments about risk disclosure is clear, and worthy of praise. Some commentators extend their interpretation further, arguing that Montgomery, together with a related House of Lords judgement, Chester $v$ Afshar [5], has motivated [18], or has completed [13], a more comprehensive protection of patient autonomy in the law of medical negligence.

There is, of course, an important background question here about the role that ethical principles play, and ought to be play, in the development of the law in this area of medical practice. It is feasible to think that the role of the court is not to give due consideration to relevant ethical values, but rather to develop its own interpretation of what is owed to patients by reference to a set of related, but independent, legal principles. If we look at recent developments across English medical law, however, this interpretation of the relationship between law and ethics in the regulation of medical decision-making is unpersuasive. The tendency for the law to proactively invoke ethical values to shape legal judgements is well-recognised in how decisions of these kinds are made in the courtroom, (e.g. [12, 24, 43]) even if important concerns have been expressed about the level of sophistication in the judicial application of these values in the legal reasoning process [6, $8,43]$. Indeed, as we suggested above, there is wide-ranging agreement amongst legal commentators that the Montgomery case was motivated by an overriding ethical imperative to respect patient autonomy-propelled, in part, by parallel professional regulatory developments-even if the judges themselves do not refer to patient autonomy explicitly as a motivating force in their judgment.

It is clear, therefore, that there is consensus between the seven judges, and between those who have examined the Montgomery judgment in depth, that the ethical principle of respect for autonomy provides the underpinning rationale for endorsing the new legal test of materiality. Whilst this direction of travel has been criticised [25], and is misaligned with the traditional and substantive distinctions between the torts of negligence and battery, our argument in this paper is different. We take issue with the very idea that the new test of materiality in the Montgomery judgment equates with respect for autonomy being given primacy in re-shaping the ongoing development of the law in this area. We aim to show that the Montgomery judgment is rightfully understood as marking a more patientcentric approach to determining what information ought to be disclosed, and how this information should be disclosed, in the informed consent process. However, notwithstanding this overarching normative realignment from practitioner-perspective to patient-perspective in the law of consent, the patient-centric approach articulated by the court is not explained by the ethical obligation to respect the patient's autonomy, and therefore that the value of autonomy needs to be deflated [41] in an adequate interpretation of this judgment. We begin, however, by providing a detailed and focused examination of the two-limbed test of materiality, adopting both methods of conceptual analysis and legal exegesis. 


\section{The 'Particular Patient'}

The majority of academic comment on Montgomery has taken the second limb of the materiality test to signify the central place that is accorded to the principle of 'respect for autonomy' [11, 18, 24, 35]. For this reason, we will scrutinise the two limbs in reverse order. The requirements of the second limb concern the legal obligation that doctors have to tailor information about risk around the values that the patient holds in the information disclosure process when they are, or should reasonably be, aware of how patients' individual values impact on a judgement about the significance of the relevant risks. This position means that the disclosure of information could potentially differ radically between two patients in exactly the same treatment situations. It is also this obligation that gives shape to the explicit recognition that patients have a legal right not to be told certain kinds of information, even if the doctor would otherwise disclose that information when obtaining consent from other patients. Whilst it is correct to say that this limb of the test demonstrates sensitivity to a patient's values in its tailoring requirement, it does not, in our view, equate with giving primacy to the principle of respecting the patient's autonomy. There are two main reasons for this.

The first reason is based on the observation that decision-making in health care that is appropriately respectful of a patient's autonomy requires information to be disclosed to the patient in ways that frame and present that information in direct response to the value commitments of that patient, in order to support that patient in governing the direction of her own life. Yet, the second limb of the materiality test, as it is expressed and considered in the judgment, is concerned with whether the particular patient would attach significance to the risk that the doctor is considering whether to disclose to her. Risk, therefore, is taken to be a pre-emptive normative consideration that shapes precisely how the patient's values ought to be taken into account in the process of disclosing information to the patient. This approach brings the patient's values into the risk disclosure equation, but it is not (at least in how the materiality test is worded) the patient's values that are driving decisions about information disclosure within the treatment encounter.

The second reason concerns the scope of the legal obligation in Montgomery to tailor information about risk disclosure around the particular patient's concerns. Risk should be disclosed, not when the particular patient accords significance to the risk, but only when the doctor is (or should reasonably be) aware of this fact. This qualification suggests a requirement on the patient to be active in disclosing relevant information about her values, or at the very least to signpost to the doctor that she has concerns of a particular kind that are relevant to the risk disclosure question and that the doctor needs to follow up on. Yet, an autonomyfocused approach would be one that required the doctor to strive herself to obtain a robust understanding of her patient's values in order to ensure that these values were respected in the treatment decisions to be made.

Importantly, this assessment of the value of autonomy in the "particular patient' limb is correct, irrespective of what theoretical account of autonomy is relied upon. Neither proceduralist nor substantive accounts of autonomy would 
countenance the idea that giving pre-emptive consideration to risk would function to ensure that, for example, the person's choices and expressed preferences about information disclosure were aligned with her higher order desires, or in order to guarantee that the patient's choices were reflective of her obligations as a moral agent. On all theoretical accounts of autonomy, the framing of information in this way would rightfully see risk as a 'contaminating element' in the exercise of the patient's autonomous agency. Equally, both individualist and relational approaches to understanding autonomy would be threatened by the fact that the doctor need only be reasonably aware that the particular patient attached significance to the relevant risks. Ensuring that the patient's choices about risk were authentic expressions of the patient's values would require the doctor to take proactive steps to probe precisely why her patient adopted a particular view about the relevant risks. Equally, on more relational accounts of autonomy, the doctor's obligation to respect the patient's autonomy would require her to establish and foster a treatment relationship with the patient within which a dialogical exchange could assist the patient to formulate her value commitments, her choices about the significance of risk, and to connect these to the specific treatment decisions to be made. Like with individualist conceptions, these relational criteria for autonomous decision-making would be undermined by interpreting the doctor's role as one founded solely on a requirement of reasonable awareness.

If the value of patient autonomy were to be the driver behind this limb of the materiality test then risk would need to be entirely absent from how a conversation about information disclosure between a doctor and her patient proceeded. In addition, it would be the doctor's responsibility to take proactive steps to learn about the values that the patient holds, and how these values connect to the question of information disclosure. Of course, we are not suggesting that information about risk would not typically be disclosed in a conversation of this kind; after all, a patient is likely to express the view that risk is a matter of concern to her in this exchange, and therefore the information provided would need to be sensitive to this concern. The basic point, however, is that the broad category of risk is significant only in so far as risk emerges as a relevant consideration in light of the patient's autonomous values given the decision being made, and the extent to which risk is articulated within a treatment relationship that is conducive to the patient formulating her value commitments in dialogue with her doctor. Framing the tailoring exercise towards the particular patient's views about risk signifies a patient-centred approach to riskdisclosure practices, but does not signify the endorsement of a 'respect for patient autonomy' principled approach to the practice of information disclosure.

\section{The 'Reasonable Person in the Patient's Position'}

We now move on to the first limb of the materiality test. This limb foregrounds a reasonableness criterion that is to be understood through a particular lens: the patient's standpoint in the treatment context. A full understanding of this limb of the test requires careful consideration of what legal and ethical work is being done by 
the notion of the 'reasonable person' here, and how this account is to be qualified by adopting a patient-centric standpoint.

It is useful to begin with some initial, general reflections on the rationale for, and the content of, the 'reasonable person' standard in English law. One of the central legal philosophical questions that arises when interrogating this standard is whether the 'reasonable person', as a legal fiction, can be articulated internally to an established system of legal rules, or whether it functions to provide a 'deregulated' extralegal anchoring of one or more values that enable the construction of normatively appropriate regulatory responses. Gardner [15] considers and defends one version of the latter account, clarifying that the role of any judge is to apply justice as a lawmaker, rather than merely to apply already existing law. Precisely what the reasonable person would think, decide, or how s/he would act in different domains of law will depend on what justice and justification call for in that domain [14].

Reinforcing our earlier remarks, this extra-legal approach to incorporating the 'reasonable person' standard into legal reasoning is compelling when we reflect on how the domain of English medical law has been broadly open to the incorporation of ethical (i.e. extra-legal) values in its reasoning around contentious health care decisions (e.g. [12, 24, 43]). The challenge for the court then becomes one of determining precisely what extra-legal anchoring work ought to be achieved when this legal fiction is invoked within the legal reasoning process. For our purposes, this gives rise to two key questions that need to be settled in any thorough analysis of the Montgomery case: (1) what legal approach is being adopted in this formulation of the standard in the law of consent to treatment, and (2) what substantive justification, if any, could underpin and defend a criterion that is formulated in this way?

The silence within Lord Kerr and Lord Reed's majority judgment concerning precisely how this standard ought to be interpreted is, to our eyes, surprising. Indeed, in reading the judgment closely, it is not entirely clear to us why, in Mrs. Montgomery's situation, this limb of the test was taken to be fulfilled as straightforwardly as it was [31].

In order to make progress on considering how the 'reasonableness' criterion ought to be made sense of, we outline what we consider to be the three most feasible interpretations of this limb of the test. To develop our understanding of this criterion, we consider a range of English and Australian jurisprudence, and reflect more broadly on approaches that have been adopted to formulating the 'reasonable person' standard in the law of medical negligence.

\section{Interpretation 1: Reasonable as Commonly Held}

The first interpretation of the 'reasonable person' standard is to replace one community standard (that of the body of expert medical opinion) with another-that of the body politic. This account of the reasonable person can be expressed formally:

$\mathbf{R P}_{\mathbf{M}}$ It is reasonable to inform a patient of risk that the majority of people think ought to be disclosed in these circumstances 
At first glance, this is an intuitively persuasive interpretation of what the 'reasonable person' standard would require. $\mathrm{RP}_{\mathrm{M}}$ is essentially an empirical account of what most people would do, if they were to find themselves in the patient's situation. Moreover, there is some limited evidence that the judges in Montgomery approached the specification of this limb of the test in this way. In potential support of this position, Lords Kerr and Reed state:

No woman would, for example, be likely to face the possibility of a fourth degree tear, a Zavenelli manoeuvre or a symphysiotomy with equanimity... This conclusion is reinforced by Dr McLellan's own evidence, that she was aware that the risk of shoulder dystocia was likely to affect the decision of a patient in Mrs Montgomery's position (para. 94).

Although it is not articulated explicitly in this quoted passage, one credible interpretation of what is meant here is to equate what the 'reasonable person in the patient position' would expect by considering what women would expect, as a matter of empirical fact, if they found themselves in Mrs. Montgomery's position. If the majority of these women would expect such information to be disclosed, then, on this formulation, it would be unreasonable to withhold it from Mrs. Montgomery.

When looking to attempts to formulate and adopt the 'reasonable person' standard more generally in medical negligence law, however, there is no support for this empirical approach to determining the 'reasonable person' approach to the application of law. For example, there is no evidence of judges looking to gather data of this kind, or to present even anecdotal statistics about how the majority of patients would conceptualise the significance of risk across different treatment scenarios. This is unsurprising; such an exercise in collecting evidence of this kind in order to specify the content of what it would be reasonable to disclose would arguably be beyond the responsibilities of a judge.

It should also be pointed out that the general consensus within the philosophy of law is the view that a significant reason for invoking the 'reasonable person' standard is to signify a decisive shift in legal regulation away from reliance on the (potentially unreasonable) views held by most people in a society or community group. In this sense, the reasonable person standard is needed so as to avoid relying on popular opinion; it cannot be articulated, therefore, by grounding itself in the cut and thrust of the majority view [22].

Importantly, there is a justificatory history to the standard interpretation of the 'reasonable person' in English law that serves to resist $\mathrm{RP}_{\mathrm{M}}$. In negligence law, and particularly in professional negligence cases, the reasonable person has been specified by reference to a particular kind of reasonable individual: the 'man on the Clapham omnibus'. It is not accidental that this version of the standard refers to one individual rather than a community of people (e.g. 'the men and women on the Clapham omnibus'). Rendering the reasonable person in terms of a particular individual clarifies that reasonableness is a feature of (some kind) of a typical, rather than communal, account of what it would be reasonable to do in the relevant circumstances [44]. Precisely what a typical account of reasonableness consists in, in this legal context, is where we now turn. 


\section{Interpretation 2: Reasonable as Logically Coherent}

A shift away from an attempt to specify the 'reasonable person' in terms of a modified communal standard leads us to interpretations that seek to connect reasonableness with justification of particular kinds. One justificatory account of reasonableness would seek to consider the rationality of a decision made, or a belief held, by the patient in question. Applying this kind of account to the Montgomery case produces a rather different picture of what the 'reasonable person' limb requires:

$\mathbf{R P}_{\mathbf{L}}$ It is reasonable to inform a patient of risk when there is logical coherence between the patient's values concerning risk and the patient's beliefs about the significance of the risk in these circumstances.

Endorsing $\mathrm{RP}_{\mathrm{L}}$ requires the patient's values and beliefs that are expressed as part of the therapeutic encounter to be probed for their 'reasonableness' prior to the doctor making a decision about what information ought to be disclosed. On this approach, the reasonable person standard would require a more substantive interrogation of the particular patient's autonomous judgement in the consent process. If this account is correct, then it also looks like the reasonable person limb of the test of materiality is operating to enhance respect for the patient's autonomy, at least on dominant procedural accounts of the value of personal autonomy.

When applied in practice, there will be examples when a 'reasonable person' would accept the coherence of the patient's values and beliefs. This looks to be the case in Mrs. Montgomery's own situation. Mrs. Montgomery had expressed a clear concern to her doctor about the anxiety she had about a vaginal delivery. She was worried both about the risks that would present to herself and her baby, given her health condition, and sought to minimise these risks. Her belief that she ought to be told about each and every risk, and to be made aware of an elective Caesarean section, are entirely consistent with the concerns and values that she held. On this interpretation of the 'reasonable person' standard, therefore, Mrs. Montgomery ought to be told of the risk of shoulder dystocia because her valuing of risk, and her beliefs about the importance of certain kinds of information about risk, were logically coherent.

In contrast, we can imagine a different situation in which a patient's beliefs about the need to be told certain information do not track the patient's value commitments in a rational manner. For example, a patient might express the view that she values a life that involves risk-taking activities, unless the risk presented is to her life. Let's imagine also that this patient says to the doctor that she doesn't want to know any risks associated with the necessary treatment, because "that's not the kind of person that she is". In a situation like this, it would not be reasonable for a doctor to withhold information about the risk of death associated with an intervention because her beliefs about the significance of risks to be disclosed does not logically cohere with her underlying values about risk.

Is $\mathrm{RP}_{\mathrm{L}}$ a valid interpretation of the 'reasonable person' standard in shaping the law of informed consent? Our concern here is that, if this was the interpretation of the 'reasonable person' standard that the judges wished to give content to the 
materiality test, they would not have drawn upon and presented the two-limbed test in the way that they did. Understood in this way, the 'reasonable person' standard would act essentially as a constraint to the exercise of the 'particular patient' standard (the second limb of the test). It would begin by considering what the particular patient ought to be told in light of their values, and then would require asking, secondly, whether it is 'reasonable' to disclose information on the basis of what the particular patient values and believes, given the logical coherence between these values and beliefs. Given that the justices did not modify the 'reasonable person' limb such that it acted as a constraint to the exercise of the 'particular patient' limb, this formulation of reasonableness is clearly not what they had in mind. As a separate standard entirely independent from the particular patient's views on the risks associated with treatment, the 'reasonable person' limb can also be recognised as capturing something other than concern about what is owed to the 'particular patient' as an autonomous agent.

\section{Interpretation 3: Reasonable as Normatively Justifiable}

The final interpretation of the 'reasonable person' standard is also one that attends to the import of a normative justificatory standard. However, in contrast to $\mathrm{RP}_{\mathrm{L}}$, which lacked moral content and simply sought to ascertain the rationality and internal coherence of a patient's values and beliefs, the final interpretation gives ethical substance to what it would be reasonable to require in the specific treatment context. Such an interpretation can be formally presented in this way:

$\mathbf{R P}_{\mathbf{N}}$ It is reasonable to inform a patient of risk that patients ought to be told in these circumstances.

There is some evidence in the Montgomery judgment that $\mathrm{RP}_{\mathrm{N}}$ was attended to, particularly in Lady Hale's minority judgment, which provided that:

[doctors] should [disclose risks] where either the mother or the child is at heightened risk from a vaginal delivery. In this day and age, we are not only concerned about risks to the baby. We are equally, if not more, concerned about risks to the mother. And these include the risks associated with giving birth, as well as any after-effects... These are risks that any reasonable mother would wish to take into account in deciding whether to opt for a vaginal delivery or a caesarean section ([32], our emphasis).

This rationale is subtly different from the approach taken by Lords Kerr and Reed. Lady Hale is suggesting that there is information relating to risk, arising in the context of pregnancy and giving birth, that it would be reasonable to take into account in the process of medical decision-making-without reference to the commonly held views that women have about risk in the same circumstances. The 'reasonable mother' is not the mother who is reasonable because she considers risk in ways that most women would do so when facing Mrs. Montgomery's situation. Rather, the 'reasonable mother' is the mother who is able to 
give appropriate moral weight to, and therefore is able to differentiate between, the significance of the risks (and benefits) that arise in the relevant situation. In reverse, it would be unreasonable to exclude from consideration information that, when disclosed, would assist the woman in question to have light shed on those interests that Lady Hale ascribes as being of moral importance for women who are pregnant or going through the process of childbirth-though, of course, the particular pregnant woman herself might not ascribe any relevance to this account of her interests in the birthing process. The distinction between $R_{P}$ and $R_{N}$ is subtle and important, but it requires further explication. It is still unclear precisely what extra-legal anchoring work is being done by the reference to 'reasonableness' in the judgment.

It is helpful at this point to revisit the High Court of Australia's judgment in Rogers $v$ Whitaker. After all, it was in this case that the test of materiality adopted by Montgomery was first articulated, and in which a woman sought negligence for not being informed about the risk of losing the sight in her left eye. Having been blind in her right eye since childhood, the very low risk of a complication that would have resulted in the loss of sight in both eyes, during an operation on her right eye, was not disclosed to the patient. In their reasoning, the six judges of the High Court of Australia considered whether the 'reasonable person in the patient's position' required the information to be disclosed. They stated:

...it could be argued, within the terms of the relevant principle as we have stated it, that the risk was material, in the sense that a reasonable person in the patient's position would be likely to attach significance to the risk, and thus required a warning. It would be reasonable for a person with one good eye to be concerned about the possibility of injury to it from a procedure which was elective ([37], our emphasis).

The point to emphasise here is that, in the context of the possibility of losing sight in both eyes, the judges recognised that it was reasonable to disclose the risk of damage to Mrs. Whitaker's normally functioning eye, whilst acknowledging that this risk might not require disclosure if the same risk of sight loss in that eye arose for a patient whose sight was not already impaired. Thus, the significance of full sight loss changes what it is reasonable to disclose, from the standpoint of the patient's position, even if the strict clinical risk of the complication arising is not itself changed by these circumstances.

Considering Rogers $v$ Whitaker alongside Montgomery is also particularly useful because it helps to clarify precisely what normative values the 'reasonable person' standard might require giving consideration to in the information disclosure process. The requirement to disclose what is reasonable, understood in this way, looks to attend to a requirement to disclose information that would impact on patients' wellbeing, understood in the broadest of terms, and in light of specific and relevant features of the treatment context. Indeed, codified within Rogers $v$ Whitaker, and first articulated in the South Australian Supreme Court case of $F v R$ [9] is the recognition of a number of explicit factors that doctors should consider when determining whether information about risk is material to the treatment decision. These include the nature of the matter to be disclosed, the nature of the treatment, the desire of the 
patient for information, the temperament and health of the patient, and the general surrounding circumstances [10].

These factors capture the importance of objective, clinically-orientated considerations about patients' well-being judged to be relevant to determining the materiality of the information to be disclosed. Aside from the point concerning the patient's desire for information, the other factors all point towards the significance of different ways in which the severity (or not) of the patient's medical circumstances, and the relationship between these circumstances and negative health outcomes for the patient, are relevant to informing (rather than determining) a judgement about whether certain risks ought to be disclosed. As has been astutely observed, the endorsement of these factors in assessing the materiality of risk in Rogers $v$ Whitaker raises questions about whether the test of materiality articulated within Australia does in fact depart substantially from the traditional application of the Bolam standard in England to similar cases pre-Montgomery, remaining dependent as it is on the application of medical expertise, and skilled professional judgment [3, 23].

This interpretation of the significance of patients' well-being captures what is normatively implicit in both the Rogers $v$ Whitaker judgment, and in the Montgomery judgment, as it is expressed by Lady Hale and outlined above. Well-being, as conceptualised in such requirements, is an objective standard, in that it attempts to capture what would it would be good for patients to know, all things considered, but one that requires interpretation from an entirely patient-centred, rather than professional-centred standpoint. This is important because it means that a narrow range of clinical facts about what would be significant to good health outcomes for patients tout court are de-centred in favour of those specific, personal interests that are relevant to the individual patient's well-being in important, nuanced ways across different treatment encounters.

Importantly, Lady Hale's judgment in Montgomery also draws attention to the significance of a broader set of subjective considerations concerning patient wellbeing that have not been well articulated or described previously. Her insistence on considering the experiential dimensions of women's interests during pregnancy and childbirth capture this contextualised, patient-centric perspective on well-being, tied, as they are, to expectations about the significance of this experience to pregnant women qua pregnant women. In this sense, it would be unreasonable to withhold information from patients that reasonable people would recognise as being relevant to shaping the experiential dimensions of treatment decisions of these kindswhether this is about the life-changing impact of becoming blind in both eyes (in Rogers $v$ Whitaker), or the inability to weigh up risks that could impact negatively on the significant and personal life events of being pregnant and experiencing giving birth (in Montgomery).

Giving due legal consideration to these subjective, experiential dimensions of well-being will likely lead the new test of materiality to depart more markedly from the application of the previous Bolam standard, and through the incorporation of more objective dimensions of patients' well-being alone. In making all-thingsconsidered practical judgements about the materiality of risk, the degree of departure from Bolam is likely to depend on the extent to which the treatment setting and specific decision connect with the significance of the patient's personal, social and 
cultural interests more broadly. This is essentially an empirical question that qualitative health research could help to clarify.

However, in general terms, whilst one might reasonably think that obstetrics practice, and, for example, psychiatric practice, would be more impacted by how the 'reasonable person' limb impacts on how patient well-being ought to be conceptualised differently, one might conclude that in surgical practice, or in other acute medical treatment contexts, patients' well-being (and, therefore, the requirements of the 'reasonable person' limb) ought to be understood in ways that remain closely aligned with a more narrowly clinical interpretation of patients' well-being interests. After all, it does not seem unreasonable, at least prima facie, to claim that the reasonable person in the patient's position would recognise that information about the likelihood and severity of risks of harm arising in a particular procedure are relevant to advancing patients' well-being in ways that point towards disclosure. Indeed, it is precisely these clinically-orientated and objective well-being considerations that judges have relied upon to inform legal judgements about the materiality of risk, post-Rogers $v$ Whitaker in Australia (e.g. [38]), and post-Montgomery in England (e.g. [34]).

In summary, then, our argument is that $\mathrm{RP}_{\mathrm{N}}$ is the accurate interpretation of the 'reasonable person in the patient position' limb, and that the account of well-being that gives reasonableness its normative content is one that should be understood (1) from patients' subjective location within a clinical encounter, (2) as potentially extending beyond clinical factors to include patients' wider personal, social and cultural interests, and (3) to arise as relevant in unique and subtle ways across different medical specialities and treatment decision-making scenarios. This interpretation does not mean relying on the majority view about what it would be reasonable to be disclosed to a patient, but it does allow for an empirical 'fleshing out' of the relevant kinds of information that substantiate patients' broad well-being interests in different treatment settings, and that ought then to be considered as appropriate to share with patients in those settings. It also follows from this interpretation that the 'reasonable person' standard can be articulated in terms that are independent from the values that are actually held by the particular patient (and therefore, in an ethical sense, the requirement to disclose information on the basis of the reasonableness standard is correctly differentiated from a requirement to respect the patient's autonomy).

Having argued for a particular conceptual interpretation of the 'reasonable person' standard that we believe best captures the argument in Montgomery, and its legal heritage, we turn now to the question of whether this normative account is fit for purpose.

\section{The Moral Terrain of Informed Consent Within the Doctor-Patient Relationship}

One of the common errors that arises in ethical and legal argumentation around consent is to interpret information disclosure requirements as a battleground along a spectrum between two essentialist moral positions: a patient-centred (and autonomy-respectful) approach at one end of the spectrum, and a doctor-centred (and 
paternalistic) approach at the other end of the spectrum. Typically, the evolution of law and practice in seen as defensible only when it shifts along this spectrum, endorsing consent practices that equate with a more patient-centred and autonomyfocused approach. One point that we have endeavoured to clarify in this paper is that, as with other areas of health care practice and research, ${ }^{1}$ patient-centrism does not, and need not, track the value of individual patient autonomy within the doctor-patient relationship, in general, and with regards to the framing and articulation of norms of information disclosure, in particular [16].

Indeed, an approach that equates patient-centred care and autonomy-respectful care risks missing what is at stake in determining how the consent process ought to function as part of good care practice within the doctor-patient relationship. It should be recognised that the doctor's shaping of the consent process is one of many moments within healthcare practice in which multiple ethical values are relevant, may be in conflict, and that need to be weighed up and balanced in a carefully reasoned manner. This is a process that does not require a specific approach to the individual act of obtaining consent, but the development of an established relationship (or set of interactions) between doctor and patient, and the fostering of a dialogical exchange, in which different values give shape to the information that is, and ought to be, shared between the two parties [19]. Established norms of shared decisionmaking are founded on precisely these tenets, adopting what has been referred to as the "shared rational deliberative joint decision" approach to medical decision-making [39]. Within such an approach, both doctor and patient.

- Ought to participate,

- Should be able to express what they find as relevant needs, interests, reasons or suggestions in light of the decision to be made,

- Should be open to seriously considering the interests and reasons of the other party, and allow their own reasons to be radically questioned,

- Should accord no priority to a single goal, interest or reason on the basis of the position of one party over the other, and.

- Should openly display all interests, goals and reasons to ensure transparency in the process of making a decision [40].

Thus, whether having arisen through chance rather than design, we broadly agree that the shift in Montgomery towards a patient-centred approach in the process of obtaining informed consent, and the two limbs of the materiality test, present the possibility of shaping informed consent practice in ways that accord with the ideals of shared decision-making within the doctor-patient relationship in the UK. The fact that the test of materiality for risk disclosure falls short of giving primacy to

\footnotetext{
1 Patient reported outcome measures (PROMS) are one such example that have gained a foothold in health services research settings. PROMS seek to ascertain the significance of certain health outcomes from the standpoint of subjective patient experience, but do not (at least in principle) give patients control over determining the outcome measures themselves, on the basis of their own preferences, values, or concerns.
} 
the individual patient's values or preferences at the heart of the process of obtaining informed consent is not a failing on behalf of the courts, but rather a way of preventing ethically appropriate shared decision-making models being blown off course by pre-emptively over-weighting one particular value. ${ }^{2}$ For this reason, we disagree with those who have claimed that Montgomery denigrates expert medical skill and judgement in the practice of obtaining informed consent [25]. Rather, the approach adopted by the Supreme Court leaves, in our view, sufficient 'elbow room for good practice' [17], requiring doctors to draw upon a range of skills and expertise in providing patient-centred care that includes making carefully reasoned decisions with patients about what information ought to be disclosed to the patient within the doctor-patient relationship.

\section{Concluding Remarks}

In drawing our arguments to a conclusion, we wish to outline some remarks about how Montgomery can be translated into healthcare practice in ways that are sensitive to our revised interpretation of the judgment. As Lords Kerr and Reed themselves clarify, doctors' practice needs to shift to capture these new legal responsibilities. They must carefully tailor the information they provide to patients, depending on the specific context of the patients' treatment needs, what it would be reasonable to disclose in this setting, and the concerns of the individual patient for whom treatment is being proposed. Secondly, this tailoring exercise is one that is entirely dependent on the doctor establishing dialogue and a therapeutic alliance with the patient in which the requisite informational parameters are able to be clarified, and in which information can be freely shared between doctor and patient. Thirdly, and finally, the process of obtaining consent is to be understood rightly as a qualitative exercise. As Lords Kerr and Reed put it:

[t]he doctor's duty is not fulfilled by bombarding the patient with technical information which she cannot reasonable be expected to grasp, let alone by routinely demanding her signature on a consent form [33].

There has been a significant degree of concern expressed amongst the medical profession about how arduous, or disadvantageous, the demands of meeting these new legal requirements will be in practice (e.g. [21, 45]). Our contention is that this concern is overblown; whilst there is novelty in the law situating informed consent requirements more centrally within a professional model of responsive and shared

\footnotetext{
${ }^{2}$ Whilst the justices can be rightfully praised for how they have incorporated and endorsed both limbs of the materiality test, there are other sections of the judgement that raise some concerns about how specific values and requirements are accorded pre-emptive legal weight. One such concern is the rightful place of the 'therapeutic privilege' that is articulated in the judgement as an exception to the two-limbed test (paras. 85; 91), rather than as a component part of it. In light of our analysis, a better understanding of the rightful place of the therapeutic privilege would be in terms of a correct, context-specific interpretation of what a 'reasonable person in the patient's position' would require not to be told because of the predicted impact of this information on patient well-being.
} 
decision-making between doctor and patient, good practice already requires this model to be the foundation upon which the doctor-patient relationship is established [4] — notwithstanding a certain degree of dissonance between optimal models of shared decision-making and the GMC's outdated guidance on information disclosure practices. ${ }^{3}$ This means that the profession is advised to clarify ways of better embedding established approaches to shared decision-making into day-to-day medical practice in order to enact their legal responsibilities correctly.

Moreover, whilst the 'reasonable person' limb replaces a narrowly clinical interpretation of patients' objective well-being with one that is built upon a broader account of patients' interests in different treatment milieus, this does not mean that information that it would be reasonable to disclose to the patient cannot be predetermined by the doctor in advance. Indeed, recent work that has looked to specify 'core information sets' [20], to be enacted in different medical specialities, goes some way to suggest how a doctor can come appropriately prepared with information that would meet the requirements of the first limb of the test of materiality in Montgomery. No doubt such information sets will be able to be refined in a continuous fashion as more complete empirical accounts of patients' broader well-being interests are specified with regards to different treatment decisions and settings.

To conclude, our claim is that the advancement of a more patient-centred approach to the law of informed consent that is endorsed in the Montgomery judgment provides new opportunities to improve patient-centred care within the doctor-patient relationship more generally. It is correct to observe that Montgomery disrupts well-recognised medical conventions around negotiating, obtaining and recording the act of informed consent, and that it brings into clearer focus the unavoidable requirement for doctors to make balanced, well-reasoned judgements between ethical values as part of their treatment encounters with patients. However, it is also correct to observe that there is nothing in Montgomery that is not firmly aligned with good medical practice as it is currently understood. The same could not have been said if the Supreme Court had devised a revised informed consent standard on the basis of an overarching and pre-emptive ethical requirement for doctors to give primacy to respecting their patients' autonomy.

Funding No funding was received to support the preparation of this manuscript.

\section{Compliance with Ethical Standards}

Conflict of interest The authors declare that they have no conflict of interest.

Ethical Statement The paper does not involve empirical research and therefore is exempt from ethics review.

\footnotetext{
${ }^{3}$ GMC. (2008). Consent: Patients and doctors making decisions together. London: General Medical Council, paras. 7-25. Whilst there is much focus on these guidelines on the doctors' responsibilities around the need to be responsive to patients' concerns, there is little attempt to clarify how the doctors' own reasons for disclosing what information it would be reasonable for patients to be told should be handled in a discussion about treatment options, other than by reference to a need to disclose information that is drawn from a pre-defined list of details that the doctor is obliged to disclose (para. 9).
} 
Open Access This article is distributed under the terms of the Creative Commons Attribution 4.0 International License (http://creativecommons.org/licenses/by/4.0/), which permits unrestricted use, distribution, and reproduction in any medium, provided you give appropriate credit to the original author(s) and the source, provide a link to the Creative Commons license, and indicate if changes were made.

\section{References}

1. Birch v University College London Hospital NHS Foundation Trust [2008] EWHC 2237 (QB).

2. Bolam v Friern Hospital Management Committee. [1957] 1 WLR 582.

3. Chalmers, D., \& Schwartz, R. (1993). Rogers $v$ Whitaker and informed consent in Australia: A fair dinkum duty of disclosure. Medical Law Review, 1, 139-159.

4. Chan, S. W., Tulloch, E., Cooper, E. S., Smith, A., Wojcik, W., \& Norman, J. E. (2017). Montgomery and informed consent: where are we now? BMJ, 357, j2224.

5. Chester v Afshar. [2004] UKHL 41.

6. Coggon, J., \& Miola, J. (2011). Autonomy, liberty, and medical decision-making. Cambridge Law Journal, 70(3), 523-547.

7. Dunlop, H. (2015). The patient's right to autonomy. 3PB Barristers. Accessed October 27, 2017 from https://www.3pb.co.uk/content/uploads/hamish_dunlop_-_montgomery_v_lanarkshir e_2015_-_briefing_-_april_2015.pdf.

8. Dunn, M., \& Foster, C. (2010). Autonomy and welfare as amici curiae. Medical Law Review, $18(1), 86-95$.

9. F v R (1983) 33 SASR 189.

10. F v R (1983) 33 SASR 189, at p. 192-193.

11. Farrell, A. M., \& Brazier, M. (2016). Not so new directions in the law of consent? Examining Montgomery $v$ Lanarkshire Health Board. Journal of Medical Ethics, 42, 85-88.

12. Foster, C. (2009). Choosing life, choosing death: The tyranny of autonomy in medical ethics and law. Oxford: Hart.

13. Foster, C. (2015). The last word on consent? New Law Journal, 7647.

14. Gardner, J. (2001). The mysterious case of the Reasonable Person. University of Toronto Law Journal, 51, 273-308.

15. Gardner, J. (2015). The many faces of the reasonable person. Law Quarterly Review, 131, 563-584.

16. Herring, J., \& Wall, J. (2015). Autonomy, capacity and vulnerable adults: filling in the gaps in the Mental Capacity Act. Legal Studies, 35(4), 698-719.

17. Herring, J., Fulford, K. W. M., Dunn, M., \& Handa, A. I. (2017). Elbow room for best practice? Montgomery, patients' values, and balanced decision-making in person-centred clinical care. Medical Law Review, 25, 582-603.

18. Heywood, R. (2015). R.I.P. Sidaway: Patient-oriented disclosure-a standard worth waiting for? Medical Law Review, 23(3), 455-466.

19. Kerridge, I., \& Mitchell, K. (1994). Missing the point: Rogers $v$ Whitaker and the ethical ideal of informed and shared decision-making. Journal of Law and Medicine, 1, 237-244.

20. Main, B. G., McNair, A. G. K., Huxtable, R., Donovan, J. L., Thomas, S. J., Kinnersley, P., et al. (2017). Core information sets for informed consent to surgical interventions: baseline information of importance to patients and clinicians. BMC Medical Ethics, 18, 29.

21. Mansell, J., \& Mansell, M. (2017). Informed consent: Montgomery trumps Bolam. Trends in Urology and Men's Health, 8(3), 10-12.

22. Miller, A. D., \& Perry, R. (2012). The reasonable person. New York University Law Review, 87, 323-392.

23. Miola, J. (2009). On the materiality of risk: Paper tigers and panaceas. Medical Law Review, 17, 76-108.

24. Miola, J., \& Heywood, R. (2017). The changing face of the pre-operative medical disclosure: Placing the patient at the heart of the matter. Law Quarterly Review, 133, 296-321.

25. Montgomery, J., \& Montgomery, E. (2016). Montgomery on informed consent: An inexpert decision? Journal of Medical Ethics, 42, 89-94.

26. Montgomery v Lanarkshire Health Board [2015] UKSC 11. 
27. Montgomery v Lanarkshire Health Board [2015] UKSC 11, at para. 87.

28. Montgomery v Lanarkshire Health Board [2015] UKSC 11, at paras. 89, 94, 104 and 109.

29. Montgomery v Lanarkshire Health Board [2015] UKSC 11, at paras. 68 and 108.

30. Montgomery v Lanarkshire Health Board [2015] UKSC 11, at paras. 56.75 and 80.

31. Montgomery v Lanarkshire Health Board [2015] UKSC 11, at para. 94.

32. Montgomery v Lanarkshire Health Board [2015] UKSC 11, at paras. 111-113.

33. Montgomery v Lanarkshire Health Board [2015] UKSC 11, at para. 90.

34. Mrs A v East Kent Hospitals University NHS Foundation Trust [2015] EWHC 1038, at para. 84 in particular.

35. Poole, N. (2015). Patient autonomy triumphs over medical paternalism. Learned Friend Blog. Accessed October 27, 2017 from https://nigelpooleqc.blogspot.co.uk/2015/03/patient-autonomytriumphs-over-medical.html.

36. Rogers v Whitaker. [1992] HCA 58; 175 CLR 479.

37. Rogers v Whitaker. [1992] HCA 58; 175 CLR 479, at para. 18.

38. Rosenberg $v$ Percival [2001] HCA 18, see Kirby J at paras. 146-149 in particular.

39. Sandman, L., \& Munthe, C. (2010). Shared decision making, paternalism and patient choice. Health Care Analysis, 18(1), 60-84.

40. Sandman, L., \& Munthe, C. (2010). See p. 78.

41. Sheehan, M. (2003). Deflating autonomy. In M. Hayry \& T. Takala (Eds.), Scratching the surface of bioethics (pp. 123-132). Amsterdam: Rodopi.

42. Sidaway v Board of Governors of the Bethlem Royal Hospital. [1985] AC 871.

43. Smith, S. W., Coggon, J., Hobson, C., Huxtable, R., McGuinness, S., Miola, J., et al. (Eds.). (2017). Ethical judgments: Re-writing medical law. Oxford: Hart.

44. This non-empirical interpretation of the legal role (of an extended group of passengers on) 'the Clapham omnibus' is reviewed and endorsed by Lord Reed in Healthcare at Home Limited v The Common Services Agency [2014] UKSC 49.

45. Welsby, P. D. (2017). Court in judgement of informed consent. Postgraduate Medical Journal, 93, $1-2$.

\section{Affiliations}

\section{Michael Dunn ${ }^{1}\left[\right.$ ' K. W. M. Fulford ${ }^{2} \cdot$ Jonathan Herring ${ }^{3} \cdot$ Ashok Handa $^{4}$}

1 The Ethox Centre, Nuffield Department of Population Health, University of Oxford, Big Data Institute Building, Old Road Campus, Headington, Oxford OX3 7LF, UK

2 Collaborating Centre for Values-based Practice in Health and Social Care, St Catherine's College, University of Oxford, Oxford OX1 3UJ, UK

3 Faculty of Law and Exeter College, University of Oxford, Oxford OX3 1DP, UK

4 Nuffield Department of Surgical Sciences, University of Oxford, John Radcliffe Hospital, Oxford OX3 9DU, UK 